Genes Genet. Syst. (2021) 96, p. 1-12

\title{
Silencing and anti-silencing mechanisms that shape the epigenome in plants
}

\author{
Soichi Inagaki ${ }^{1,2 *}$ \\ ${ }^{1}$ Department of Biological Sciences, Graduate School of Science, The University of Tokyo, Bunkyo-ku, \\ Tokyo 113-0033, Japan \\ ${ }^{2}$ PRESTO, Japan Science and Technology Agency, Kawaguchi, Saitama 332-0012, Japan
}

(Received 6 June 2021, accepted 30 July 2021; J-STAGE Advance published date: 29 October 2021)

\begin{abstract}
Epigenome information mediates genome function and maintenance by regulating gene expression and chromatin organization. Because the epigenome pattern can change in response to internal and external environments, it may underlie an adaptive genome response that modulates phenotypes during development and in changing environments. Here I summarize recent progress in our understanding of how epigenome patterns are shaped and modulated by concerted actions of silencing and anti-silencing factors mainly in Arabidopsis thaliana. I discuss the dynamic nature of epigenome regulation, which is realized by cooperation and counteraction among silencing and anti-silencing factors, and how the dynamic epigenome mediates robust and plastic responses of plants to fluctuating environments.
\end{abstract}

Key words: silencing, anti-silencing, epigenome, plants, environmental response

\section{INTRODUCTION}

Epigenetic inheritance is defined as the stable transmission of information that is not directly encoded in the genome sequence (Holliday, 1987; Richards, 2006; Heard and Martienssen, 2014). The molecular basis of epigenetic inheritance is epigenome marks, which decorate chromatin, the molecular component of the chromosome. Studies in the past 30 years have discovered many epigenome marks and their roles and molecular mechanisms in numerous eukaryotic species. A model plant, Arabidopsis thaliana (hereafter called Arabidopsis), has been playing key roles in elucidating the molecular mechanisms to regulate DNA methylation (5-methylcytosine), one of the best-characterized epigenomic marks that is conserved in many eukaryotic species (Law and Jacobsen, 2010; Zhang et al., 2018b). One important function of DNA methylation in plants and vertebrates is the defense

\footnotetext{
Edited by Kenji Ichiyanagi

* Corresponding author. soinagak@bs.s.u-tokyo.ac.jp DOI: https://doi.org/10.1266/ggs.21-00041
}

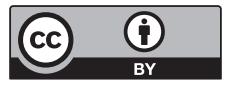

Copyright: (02021 The Author(s). This is an open access article distributed under the terms of the Creative Commons BY 4.0 International (Attribution) License (https://creativecommons.org/ licenses/by/4.0/legalcode), which permits the unrestricted distribution, reproduction and use of the article provided the original source and authors are credited. against parasitic genetic elements, transposable elements (TEs) (Lippman et al., 2004; Slotkin and Martienssen, 2007; Lisch and Bennetzen, 2011; Hosaka and Kakutani, 2018). DNA methylation silences transcription and mobilization (transposition) of TEs (Miura et al., 2001; Singer et al., 2001; Mirouze et al., 2009; Tsukahara et al., 2009). Therefore, TEs have been serving as model targets to elucidate the genetic and molecular mechanisms of epigenetic gene silencing. In the past two decades, elaborate molecular mechanisms that use small interfering RNA (siRNA) and/or histone modifications/variants, other conserved epigenome marks, as guides to target DNA methyltransferases specifically to TE regions have been elucidated (Lisch, 2009; Saze and Kakutani, 2011; Kim and Zilberman, 2014). However, no system works without having counteracting mechanisms. To prevent DNA methylation and associated gene silencing from running out of control, organisms should have anti-silencing mechanisms. Compared with silencing, anti-silencing mechanisms are not well understood.

This review focuses on the genetic and molecular mechanisms that underlie the antagonism between silencing and anti-silencing and their implication in chromatinbased mechanisms of gene expression programs. First, I summarize silencing and anti-silencing factors that have been characterized so far, especially in Arabidopsis (factors are summarized in Table 1). Then, I discuss how silencing and anti-silencing factors interact with each other to shape the epigenome landscape. Finally, 
Table 1. Silencing and anti-silencing factors discussed in this review

\begin{tabular}{|c|c|c|c|c|c|}
\hline & Category & Name & Function & Targets & Control \\
\hline \multirow{18}{*}{ Silencing } & \multirow{5}{*}{$\begin{array}{l}\text { DNA } \\
\text { methylation }\end{array}$} & MET1 & CG methylation & genes, TEs & $\begin{array}{l}\text { Maintenance in } \\
\text { DNA replication }\end{array}$ \\
\hline & & CMT3 & CHG methylation & TEs, (genes)* & $\begin{array}{l}\text { Feed-forward loop } \\
\text { with H3K9me1/2 }\end{array}$ \\
\hline & & CMT2 & CHH methylation & TEs & $\begin{array}{l}\text { Feed-forward loop } \\
\text { with H3K9me2 }\end{array}$ \\
\hline & & DRM2 & C methylation & TE fragments & RdDM \\
\hline & & DDM1 & C methylation & TEs & Deposition of H2A.W \\
\hline & \multirow{11}{*}{$\begin{array}{l}\text { Histone } \\
\text { modification }\end{array}$} & $\begin{array}{l}\text { SUVH4/ } \\
\text { KRYPTONITE }\end{array}$ & H3K9me1/2 & TEs, (genes)* & Feed-forward loop with $\mathrm{mCH}$ \\
\hline & & SUVH5 & H3K9me1/2 & TEs & Feed-forward loop with $\mathrm{mCH}$ \\
\hline & & SUVH6 & H3K9me1/2 & TEs & Feed-forward loop with $\mathrm{mCH}$ \\
\hline & & AGDP1/ADCP1 & $\begin{array}{l}\mathrm{H} 3 \mathrm{~K} 9 \mathrm{me} 2 / \mathrm{mC} \\
\text { maintenance }\end{array}$ & TEs & Binding to H3K9me \\
\hline & & ATXR5 & H3K27me1 & TEs & Methylation of H3.1 \\
\hline & & ATXR6 & $\mathrm{H} 3 \mathrm{~K} 27 \mathrm{me} 1$ & TEs & Methylation of H3.1 \\
\hline & & CLF & H3K27me3 & repressed genes & Interplay with H3K27me1? \\
\hline & & MEA & H3K27me3 & repressed genes & Interplay with H3K27me1? \\
\hline & & SWN & H3K27me3 & repressed genes & Interplay with H3K27me1? \\
\hline & & LDL2 & H3K4me1 demethylation & genes, $(\mathrm{TEs})^{*}$ & $\begin{array}{l}\text { Induced by } \mathrm{H} 3 \mathrm{~K} 9 \mathrm{me} 2 \text { in } \\
\text { transcribed regions }\end{array}$ \\
\hline & & FLD & H3K4me1 demethylation & $\begin{array}{l}\text { genes with antisense } \\
\text { transcription }\end{array}$ & $\begin{array}{l}\text { Induced by antisense } \\
\text { transcription }\end{array}$ \\
\hline & \multirow{2}{*}{$\begin{array}{l}\text { Histone } \\
\text { variant }\end{array}$} & H2A.W & Transcription silencing & TEs & Deposition by DDM1 \\
\hline & & H3.1 & H3K27me1/3 maintenance & TEs, genes & $\begin{array}{l}\text { DNA replication-coupled } \\
\text { incorporation }\end{array}$ \\
\hline \multirow{7}{*}{$\begin{array}{l}\text { Anti- } \\
\text { silencing }\end{array}$} & \multirow{5}{*}{$\begin{array}{l}\text { DNA } \\
\text { demethylation }\end{array}$} & ROS1/DML1 & $\mathrm{mC}$ demethylation & $\begin{array}{l}\text { TEs located close } \\
\text { to genes }\end{array}$ & Antagonize with RdDM \\
\hline & & DML2 & $\mathrm{mC}$ demethylation & $\begin{array}{l}\text { TEs located close } \\
\text { to genes }\end{array}$ & Antagonize with RdDM \\
\hline & & DML3 & $\mathrm{mC}$ demethylation & $\begin{array}{l}\text { TEs located close } \\
\text { to genes }\end{array}$ & Antagonize with RdDM \\
\hline & & DME & $\mathrm{mC}$ demethylation & $\begin{array}{l}\text { TEs located close } \\
\text { to genes }\end{array}$ & Activated in the central cell \\
\hline & & VanC & $\begin{array}{l}\text { Transposition of Vandal TEs, } \\
\text { associated with DNA } \\
\text { demethylation }\end{array}$ & $\begin{array}{l}\text { Vandal TEs of } \\
\text { specific families }\end{array}$ & $\begin{array}{l}\text { Binding to tandem repeats } \\
\text { with binding motifs }\end{array}$ \\
\hline & \multirow{2}{*}{$\begin{array}{l}\text { H3K9 } \\
\text { demethylation }\end{array}$} & IBM1 & H3K9 demethylation & genes, $(\mathrm{TEs})^{*}$ & $\begin{array}{l}\text { Induced by transcription } \\
\text { of the target genes }\end{array}$ \\
\hline & & JMJ27 & H3K9 demethylation & Defense genes? & $\begin{array}{l}\text { Upregulated by } \\
\text { pathogen infection }\end{array}$ \\
\hline
\end{tabular}

*, facultative target.

I review recent progress in elucidating mechanisms that utilize the epigenome to regulate gene expression in response to a fluctuating environment.

\section{FACTORS INVOLVED IN SILENCING AND ANTI-SILENCING}

\section{Silencing}

DNA methylation In plants, cytosine methylation $(\mathrm{mC})$ occurs in three sequence contexts, CG, CHG and $\mathrm{CHH}$ ( $\mathrm{H}=\mathrm{A}, \mathrm{T}$ or $\mathrm{C}$ ), each of which is regulated by distinct 
mechanisms (Law and Jacobsen, 2010). CG sites are generally methylated symmetrically (both strands are methylated), and CG methylation ( $\mathrm{mCG}$ ) is stably inherited through mitosis and meiosis, via DNA replicationcoupled maintenance methylation by METHYLTRANSFERASE1 (MET1) (Kankel et al., 2003; Saze et al., 2003). In Arabidopsis and other plants, mCG is found in repetitive genetic elements (e.g., TEs) and the transcribed regions (gene body) of actively transcribed genes (Cokus et al., 2008; Lister et al., 2008). The latter is referred to as gene body methylation (gbM), although its function is still unknown. gbM is not associated with silencing, probably because the transcription start sites (TSSs) and promoters of genes containing gbM are free from $\mathrm{mC}$ (Inagaki and Kakutani, 2012). Interestingly, gbM is the most conserved feature of DNA methylation in eukaryotes; even invertebrates without $\mathrm{mC}$ in repetitive sequences have gbM (Feng et al., 2010; Zemach and Zilberman, 2010; Zemach et al., 2010). Therefore, gbM may be an ancient form of DNA methylation. $\mathrm{mCHG}$ and $\mathrm{mCHH}$ (collectively referred to as non-CG methylation or $\mathrm{mCH}$ ) are generally associated with TEs and silenced genes (Cokus et al., 2008; Lister et al., 2008; Zemach et al., 2013; Stroud et al., 2014). CHG and CHH sites are methylated by CHROMOMETHYLASE3 (CMT3) and CMT2, respectively, in a self-reinforcing mechanism with histone H3 lysine-9 (H3K9) methylation (discussed later). In addition, $\mathrm{C}$ at all contexts can be methylated via RNA-dependent DNA methylation (RdDM). siRNAs of 24 nucleotides, transcribed from methylated regions by RNA polymerase IV complex and processed by RNAdependent RNA polymerase and Dicer proteins, guide DOMAINS REARRANGED METHYLTRANSFERASE2 (DRM2) to its target sequences. To date, many factors involved in RdDM have been identified (Matzke and Mosher, 2014; Erdmann and Picard, 2020). In addition to this 'canonical RdDM', which maintains and reinforces $\mathrm{mC}$ in previously methylated regions, plants have 'noncanonical RdDM', which methylates de novo at new target loci (e.g., newly inserted TEs). Noncanonical RdDM uses the same molecular components as RNA interference or posttranscriptional gene silencing and is guided by 21-22-nucleotide siRNAs to recruit DRM2 to target loci (Cuerda-Gil and Slotkin, 2016). Once a certain level of methylation/silencing is established, canonical RdDM takes over to maintain and reinforce the silencing (Cuerda-Gil and Slotkin, 2016). Recently, it has been shown that $\mathrm{mCHG}$ and $\mathrm{mCHH}$ in the transcribed (coding) regions of TEs can be established de novo in the absence of RdDM, after almost complete erasure of $\mathrm{mCHG} / \mathrm{mCHH}$ (To et al., 2020). This result illuminates the presence of hitherto-unknown mechanism(s) to establish DNA methylation patterns. This establishment of $\mathrm{mCH}$ in the coding regions of TEs seems to be mediated by an antagonistic mechanism between silencing and anti-silencing factors such as H3K9 demethylation and exchange of histone variants (To et al., 2020), as discussed later.

Another well-characterized silencing mechanism involving DNA methylation is by the SWI2/SNF2 chromatin remodeler protein Decrease in DNA Methylation (DDM1; Jeddeloh et al., 1999). Loss-of-function mutations of the $D D M 1$ gene cause $\sim 70 \%$ loss of $\mathrm{mC}$ genome-wide (Vongs et al., 1993). The loss of $\mathrm{mC}$ occurs mainly within the transcription units of TEs that have highly heterochromatic features (Lippman et al., 2004; Zemach et al., 2013) and is accompanied by loss of H3K9 methylation (Gendrel et al., 2002). How DDM1 mediates DNA methylation and TE silencing is still largely unknown, but several reports have proposed its mechanism of action. It was reported that the loss of $\mathrm{mC}$ in $d d m 1$ mutants was suppressed by a loss of the linker histone H1 (Zemach et al., 2013), suggesting that DDM1 counteracts $\mathrm{H} 1$ to make chromatin accessible to DNA methyltransferases. A more recent report has shown that DDM1 mediates the deposition of histone variant H2A.W onto heterochromatic TEs, which leads to the silencing of TEs (Osakabe et al., 2021; discussed later). Interestingly, $d d m 1$-induced loss of $\mathrm{mC}$ progressively occurs across generations (Kakutani et al., 1996), and in later generations, localized hypermethylation in a widespread hypomethylation background is induced (Saze and Kakutani, 2007; Sasaki et al., 2012; Ito et al., 2015), suggesting that the disturbance of silencing and anti-silencing is triggered by the loss of DDM1.

H3K9me Histone marks are posttranslational modifications, such as methylation, acetylation, ubiquitination and phosphorylation, on histone proteins H2A, H2B, H3 and $\mathrm{H} 4$, which constitute the histone octamer, the nucleosome core particle (Allis and Jenuwein, 2016). Specific modifications at specific residues of histone proteins can be viewed as a histone code that dictates specific chromatin-based processes such as transcription, DNA replication/repair and higher-order chromatin organization. H3K9 methylation (the lysine can be mono-, di- or trimethylated; collectively referred to as $\mathrm{H} 3 \mathrm{~K} 9 \mathrm{me}$ ) is one of the most conserved histone marks, and is involved in silencing and heterochromatin formation. In plants, H3K9 monomethylation (H3K9me1) and dimethylation (H3K9me2) are tightly associated with heterochromatin and localize to silenced TEs (Bernatavichute et al., 2008; Stroud et al., 2014). Three SUVH family methyltransferases, SUVH4, SUVH5 and SUVH6, partially redundantly catalyze H3K9me1/2 (Ebbs and Bender, 2006; Du et al., 2015). In animals and fungi, H3K9me is recognized by heterochromatin protein 1 (HP1) family proteins via a chromodomain that directly binds to methylated H3K9, and then triggers chromatin condensation and transcriptional silencing (Maison and Almouzni, 2004). However, the homolog of HP1 in plants, TERMINAL FLOWER 2/ LIKE-HETEROCHROMATIN PROTEIN1 (TFL2/LHP1), 
is involved in the recognition of H3K27me3 (Turck et al., 2007; Zhang et al., 2007), and, instead, other protein(s) are responsible for the recognition of H3K9me in plants. Two such proteins are the plant-specific DNA methyltransferases, CMT2/3. CMT2/3 have a chromodomain and a bromo-adjacent homology domain, both of which are involved in the binding to H3K9me1/2 (Du et al., 2012). As a result, $\mathrm{H} 3 \mathrm{~K} 9 \mathrm{me} 1 / 2$ induces $\mathrm{mCHG}$ and $\mathrm{mCHH}$ catalyzed by $\mathrm{CMT} 3$ and $\mathrm{CMT} 2$, respectively (Bernatavichute et al., 2008; Miura et al., 2009; Inagaki et al., 2010; Zemach et al., 2013; Stroud et al., 2014). mCHG and $\mathrm{mCHH}$ in turn induce H3K9me1/2 by SUVH4/5/6 proteins, as SUVH proteins have an SRA domain that specifically binds to $\mathrm{mC}$ (the preference for cytosine context varies among SUVH proteins) (Johnson et al., 2007; Du et al., 2014). Therefore, H3K9me1/2 and $\mathrm{mCH}$ constitute a self-reinforcing loop (Fig. 1), which maintains and amplifies the silencing signal for a robust silencing of TEs (Inagaki et al., 2010; Law and Jacobsen, 2010; Du et al., 2015). Other proteins that recognize H3K9me and are involved in silencing have also been identified (Zhang et al., 2018a; Zhao et al., 2019a).

H2A.W Histone H2A has some variant forms, one of which is the vascular plant-specific $\mathrm{H} 2 \mathrm{~A}$ variant H2A.W. H2A.W is encoded by three genes in Arabidopsis, and is distinct in its $\mathrm{C}$-terminal sequence and genome-wide localization from other H2A variants (Yelagandula et al., 2014). H2A.W localizes at heterochromatic TEs, where it colocalizes with $\mathrm{H} 3 \mathrm{~K} 9 \mathrm{me} 1 / 2$, and is absent in active genes. Specific localization of H2A.W is not affected in the suvh4/5/6 mutant, which loses H3K9me1/2. Conversely, the loss of H2A.W does not induce alterations of H3K9me1/2 or H3K27me1, other silencing-associated histone marks mentioned above and below, respectively (Bourguet et al., 2021). These results are consistent with the view that H2A.W, H3K9me1/2 and H3K27me1 are independent silencing marks. However, the loss of $\mathrm{H} 2 \mathrm{~A}$. W induces a mild decrease in $\mathrm{mCHG} / \mathrm{mCHH}$ in heterochromatic TEs, in which H2A.W normally localizes in wild-type plants (Bourguet et al., 2021). This decrease of $\mathrm{mCHG} / \mathrm{mCHH}$ in the $h 2 a . w$ mutant was suppressed by loss of the linker histone H1, suggesting that H2A.W regulates $\mathrm{mCH}$ by antagonizing the deposition of $\mathrm{H} 1$ into heterochromatin and then facilitating the access of DNA methylases there (Fig. 1). This idea was supported by genomic H1 localization data and ATAC-seq (assay for transposase-accessible chromatin using sequencing) for chromatin accessibility (Bourguet et al., 2021).

As mentioned above, DDM1 binds to and mediates the chromatin recruitment of H2A.W (Osakabe et al., 2021). DDM1 binds to H2A.W via its two small and conserved domains. Remarkably, full-length DDM1 protein, but not mutant DDM1 that lacks H2A.W-binding domains, can induce TE silencing, independently of $\mathrm{H} 3 \mathrm{~K} 9 \mathrm{me} 2 / \mathrm{mC}$ (Osakabe et al., 2021). These results suggest that the primary function of DDM1 in TE silencing is the chromatin deposition of H2A.W into TEs and that this is mechanistically separable from the maintenance of H3K9me2/ $\mathrm{mC}$ by DDM1 (Fig. 1). Interestingly, the mammalian ortholog of DDM1, Lymphoid-Specific Helicase (LSH), has also been shown to mediate the deposition of a heterochromatic H2A variant, microH2A (Ni et al., 2020), illustrating a conserved mechanism of silencing regulation by a chromatin remodeler and an $\mathrm{H} 2 \mathrm{~A}$ variant.

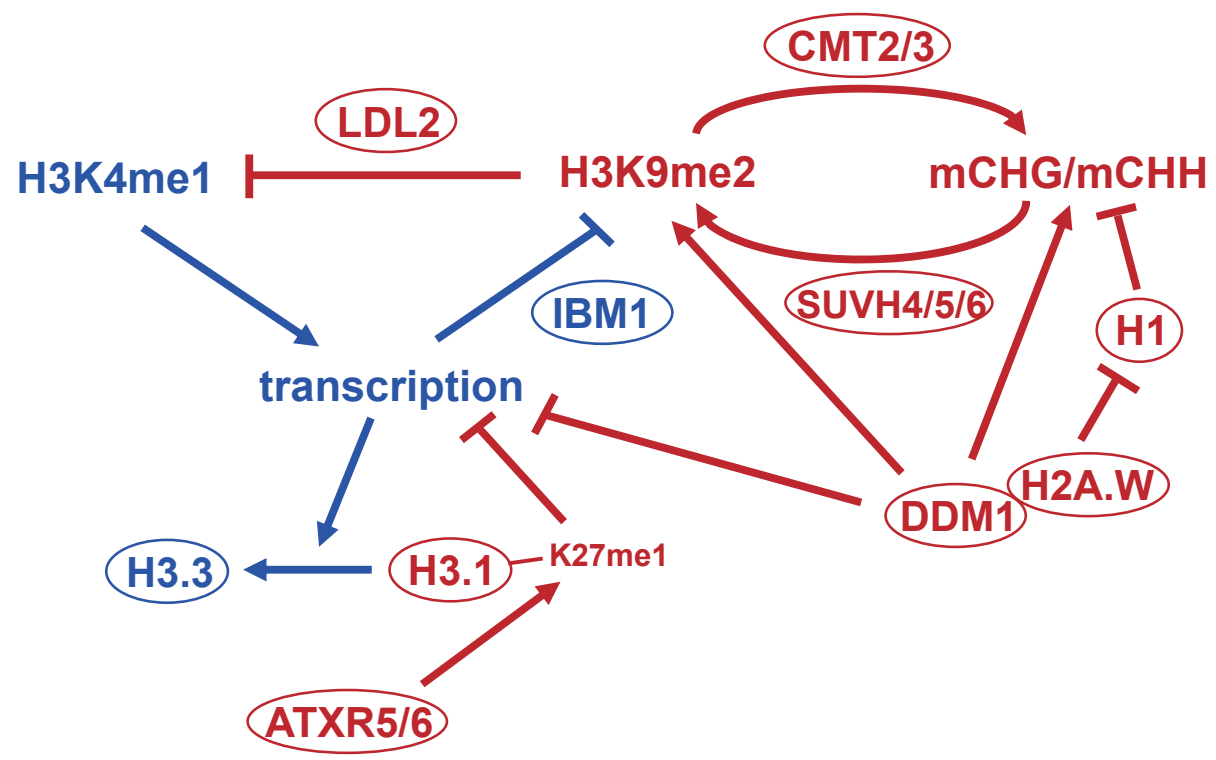

Fig. 1. A model for epigenome regulation in the transcribed regions of full-length genes/TEs. Silencing factors and marks are depicted in red, and anti-silencing factors and marks are in blue. See the text for details. 
H3K27me1 H3K27 monomethylation (H3K27me1) is a histone mark localized specifically to silenced TEs, like H3K9me1/2 and H2A.W. H3K27me1 is catalyzed by two SET domain-containing proteins, ARABIDOPSIS TRITHORAX-RELATED 5/6 (ATXR5/6; Jacob et al., 2009). The double mutant atxr5/6, which loses H3K27me1, does not affect DNA methylation or H3K9me2 but causes reactivation and overreplication of heterochromatic TEs (Jacob et al., 2009, 2010). Therefore, H3K27me1 acts as a silencing mark, in parallel with H3K9me2/mC. ATXR5/6 selectively methylate an H3 variant, H3.1, which is incorporated into chromatin in a replication-coupled manner, over the transcriptioncoupled H3 variant H3.3 (Jacob et al., 2014). Alanine and threonine residues at position 31 in H3.1 and H3.3, respectively, are responsible for this differential sensitivity to ATXR5/6. These results illuminate a simple mechanism that transmits the silencing histone mark in heterochromatin through DNA replication and prevents the spread of silencing to H3.3-rich active genes (antisilencing; Fig. 1).

H3K27me3 In contrast to the above-mentioned silencing marks, H3K27 trimethylation (H3K27me3) is usually associated with genes that are expressed in a tissue-specific manner or in response to environmental change. H3K27me3 is viewed as a mark to regulate tissue-specific or responsive gene expression in plants and animals. Conserved Polycomb Repressive Complex 2 (PRC2) proteins, CURLY LEAF (CLF), MEDEA (MEA) and SWINGER (SWN), are methyltransferase proteins responsible for H3K27me3 (Baumbusch et al., 2001; Köhler and Villar, 2008). I do not discuss H3K27me3 in detail here, because two excellent reviews cover the field of polycomb repression in development and responses to the environment (Mozgova and Hennig, 2015; Xiao and Wagner, 2015).

One notable finding regarding $\mathrm{H} 3 \mathrm{~K} 27 \mathrm{me} 3$, which is related to another silencing mark, is that the stable inheritance of $\mathrm{H} 3 \mathrm{~K} 27 \mathrm{me} 3$ is dependent on DNA replication-coupled H3.1 incorporation, and Ala/Thr-31 of H3.1/ H3.3 plays a role in this mechanism (Jiang and Berger, 2017). Although the mechanistic link between ATXR5/6mediated H3K27me1 and PRC2-mediated H3K27me3 is currently elusive, it is interesting from the point of view of stable inheritance of silencing/anti-silencing state based on DNA replication-coupled and transcription-coupled histone variant incorporation into chromatin.

Another finding of note is that in the unicellular eukaryote Paramecium tetraurelia, Enhancer-of-zestelike protein, Ezl1, which shares an origin with plant and animal H3K27 trimethylases, catalyzes both H3K27me3 and H3K9me3 (Frapporti et al., 2019). In Paramecium, H3K27me3 and H3K9me3 co-occur in silenced TEs, and Ezl1 knockdown induces a massive reactivation of these
TEs. Roles of PRC2/H3K27me3 in TE silencing have also been reported in other ciliates and diatoms (Liu et al., 2007b; Veluchamy et al., 2015; Zhao et al., 2019b). These results suggest that, in contrast to plants and animals, H3K27me3 (as well as H3K9me) mediated by the PRC2 complex play a key role in TE silencing in protists, and this could be the ancestral function of H3K27me3, which might later have been co-opted for developmental regulation in multicellular eukaryotes such as plants and animals. Cooperation between H3K27me3 and H3K9me or other silencing marks in gene and TE silencing is also reported in plants and animals (Deleris et al., 2012; Mozzetta et al., 2014; Wiles and Selker, 2017; Montgomery et al., 2020).

\section{Anti-silencing}

DNA demethylation One mechanism of anti-silencing is the removal of silencing marks. In addition to passive demethylation of DNA through DNA replication, active DNA demethylation mechanisms play important roles in confining $\mathrm{mC}$ to specific regions of the genome. The DNA glycosylase proteins REPRESSOR OF SILENCING 1 (ROS1), DEMETER (DME) and DME-LIKE2 and 3 (DML2/3) trigger DNA demethylation through the baseexcision repair pathway (Zhu, 2009). DNA demethylation is implicated in several biological processes such as imprinting in the endosperm (Bauer and Fischer, 2011), pollen tube formation (Schoft et al., 2011; Khouider et al., 2021) and biotic and abiotic stress responses (Liu and Lang, 2020), illustrating that regulated DNA demethylation is an important mechanism for developmentally or environmentally induced gene expression. In the central cell, the companion cell of the egg, and the vegetative cell, the companion cell of the sperm, extensive DNA demethylation of TEs by DME induces loss of silencing (Calarco et al., 2012; Ibarra et al., 2012; Kawashima and Berger, 2014; Park et al., 2016). The reactivated TEs in the companion cells are proposed to reinforce TE silencing in the gametes by mobile small-RNA-mediated mechanisms (Slotkin et al., 2009; Calarco et al., 2012; Ibarra et al., 2012; Martínez et al., 2016) or to act as distal regulatory elements to activate genes involved in the functions of the companion cells (Borg et al., 2021). The anti-silencing mechanism in the companion cells, whose genomic and epigenomic information is not inherited by the next generation, can be viewed as an essential part of the silencing mechanism of potentially harmful TEs in the germline.

The targeting mechanism of DNA demethylases to specific regions of the genome is important for the correct anti-silencing mechanism. Genome-wide analysis of $\mathrm{mC}$ in the triple mutant ros $1 \mathrm{dml} 2 \mathrm{dml} 3$ showed that it accumulates $\mathrm{mC}$ in all contexts around 5' and 3' ends of protein-coding genes, at which the $\mathrm{mC}$ level is usually low in wild type plants (Penterman et al., 2007; Lister et al., 2008). More recently, a higher-resolution methylome 
and extensive analyses in the ros 1 mutants in two different genetic backgrounds revealed that ROS1 demethylates TEs located close to protein-coding genes and that most of these TEs are antagonistically regulated by ROS1 and RdDM (Tang et al., 2016). The study revealed many sequences that are not methylated in wild type but are in the ros 1 mutant in an RdDM-dependent manner, illuminating that the balance between silencing by RdDM and anti-silencing by ROS1 determines the DNA methylation state in each TE, which influences the activity of neighboring genes (Tang et al., 2016). The target of ROS1 may be determined by histone modifications (Qian et al., 2012; Tang et al., 2016) and a histone variant, H2A.Z (Nie et al., 2019). H2A.Z and $\mathrm{mC}$ are known to show exclusive localization in the genome (Zilberman et al., 2008), and H2A.Z plays a role in demethylating $\mathrm{mCG}$ around TSSs of TEs in the cmt2 cmt3 mutant, which loses mCHG/ $\mathrm{mCHH}$ (To et al., 2020). H2A.Z, especially around TSSs, is thought to function as an anti-silencing mark by counteracting DNA methylation.

VanCs - Transposon-encoded sequence-specific antisilencing factors One unique anti-silencing mechanism is conferred by the VanC proteins encoded in Vandal family TEs. In contrast to most other anti-silencing mechanisms, anti-silencing by VanCs only induces reactivation of closely related families of Vandal TEs (Fu et al., 2013; Hosaka et al., 2017). Exogenous expression (from a transgene) of VanC21 from a Vandal21 TE causes specific loss of $\mathrm{mC}$ within endogenous Vandal21 loci, and elevated transcription of genes encoded in these TEs. Similarly, VanC protein from Vandal6 TE causes loss of $\mathrm{mC}$ within endogenous Vandal6 and closely related Vandal TEs (Hosaka et al., 2017). VanC21 protein localizes to the non-coding regions within Vandal21 TEs by recognizing specific DNA motifs, which have proliferated through tandem repeat formation. VanC21, a previously uncharacterized sequence-specific DNA-binding protein, and its binding DNA motifs, therefore, have likely coevolved to acquire a self-anti-silencing mechanism, which counteracts the host silencing mechanisms and at the same time reduces the negative effect on genome integrity by maintaining the overall defense against TEs (Hosaka and Kakutani, 2018; Cosby et al., 2019).

H3K9 demethylation H3K9me (H3K9me1/2 in plants) is known to be associated with constitutively silenced sequences in heterochromatin. However, several studies have revealed the reversible and dynamic nature of H3K9me, which plays an important role in development and adaptation to the environment. Proteins containing JumonjiC (JmjC) domains have histone demethylase activity, which can reverse histone methylation at specific sites (Klose et al., 2006; Tsukada et al., 2006). Several $\mathrm{JmjC}$ family proteins that can demethylate H3K9me have been reported in mammals (Cloos et al., 2006; Fodor et al., 2006; Yamane et al., 2006) and plants (Saze et al., 2008; Sun and Zhou, 2008; Inagaki et al., 2010). The Arabidopsis H3K9 demethylase gene IBM1 (Increased BONSAI Methylation 1) is required to prevent the accumulation of $\mathrm{mCHG} / \mathrm{mCHH}$ in the bodies of thousands of active genes and for normal development (Saze et al., 2008; Miura et al., 2009). The loss of IBM1 induces the self-reinforcing loop of SUVH4 and CMT3 (and probably CMT2) to cause ectopic accumulation of both $\mathrm{mCHG} / \mathrm{mCHH}$ and H3K9me2 in the bodies of active genes (Saze et al., 2008; Inagaki et al., 2010). Therefore, counteraction between silencing factors (SUVH and CMT proteins) and an antisilencing factor (IBM1) establishes the border between active and inactive chromatin domains (Fig. 1). Interestingly, while the accumulation of $\mathrm{mCH} / \mathrm{H} 3 \mathrm{~K} 9 \mathrm{me} 2$ within active genes in the $i b m 1$ mutant is suppressed by suvh4 or cmt 3 mutation, the loss of $\mathrm{mCH} / \mathrm{H} 3 \mathrm{~K} 9 \mathrm{me} 2$ within TEs in the suvh4 or cmt3 mutants is partially suppressed by ibm 1 mutation (Inagaki et al., 2010). Moreover, these TEs that are antagonistically regulated by SUVH4/CMT3 and IBM1 are transcriptionally activated in suvh4 or cmt3. These results revealed that the borders between active and inactive chromatin domains are plastic and regulated by dynamic relationships between silencing and anti-silencing mechanisms. Consistent with this view, H3K9 demethylation by IBM1 counteracts the establishment of silencing marks, $\mathrm{mCHG} / \mathrm{mCHH}$, after their almost complete erasure (To et al., 2020), showing that the antagonism between silencing and anti-silencing also plays an important role in the establishment of the epigenome pattern.

The fission yeast jmjC protein Epe1 has been shown to function as an anti-silencing factor to prevent ectopic heterochromatin formation and to counteract epigenetic inheritance of siRNA-induced silencing (Zofall and Grewal, 2006; Trewick et al., 2007; Audergon et al., 2015; Ragunathan et al., 2015; Wang et al., 2015; Sorida et al., 2019), although direct evidence of its H3K9 demethylase activity is still lacking. Paradoxically, Epe1 is also important to maintain silencing in heterochromatin, partly because Epe1 is required to transcribe the heterochromatin region to produce siRNAs that trigger heterochromatin formation with H3K9 methylation (Zofall and Grewal, 2006; Trewick et al., 2007). Epe1 secures stable inheritance of silenced and active chromatin states by coordinating heterochromatin formation and anti-silencing (Trewick et al., 2007; Sorida et al., 2019). A recent report revealed that a decrease in Epe1 protein level is triggered by a low or medium dose of caffeine, which induces heterochromatin formation in euchromatic genes and the emergence of caffeine-resistant epi-mutants (Torres-Garcia et al., 2020), suggesting that modulation of an anti-silencing mechanism is an adaptive genome response to environmental changes, which potentially 
creates heritable epigenetic variations. The mammalian H3K9 demethylases are important in spatiotemporal gene regulation (Yamane et al., 2006; Okada et al., 2007; Tateishi et al., 2009; Kuroki et al., 2013), highlighting the dynamic nature of $\mathrm{H} 3 \mathrm{~K} 9 \mathrm{me}$ and the importance of antisilencing mechanisms also in mammals.

\section{INTERACTION AMONG SILENCING AND ANTI- SILENCING FACTORS}

As discussed above, a certain silencing mechanism is antagonized by a specific anti-silencing mechanism. For example, RdDM and DNA demethylases antagonistically regulate TEs that are inserted close to genes. Silencing regulation by $\mathrm{H} 3 \mathrm{~K} 27 \mathrm{me} 1$ is counteracted by transcription-coupled deposition of H3.3 in the bodies of active genes. $\mathrm{H} 3 \mathrm{~K} 9 \mathrm{me} 2 / \mathrm{mCH}$ is antagonistically regulated by SUVH4/5/6 - CMT2/3 and IBM1 to differentiate active and inactive chromatin states of genes and TEs. Therefore, counteraction between silencing and anti-silencing seems to be an essential principle of epigenome regulation.

An additional important mechanism to shape and maintain correct epigenome patterns is feedback regulation. One such mechanism is regulated through $\mathrm{mC}$ around the TSS of the ROS1 gene. As mentioned above, $\mathrm{mC}$ around a TSS usually silences transcription; however, RdDM-mediated $\mathrm{mC}$ around the TSS of ROS1 positively regulates ROS1 expression (Lei et al., 2015; Williams et al., 2015). This $\mathrm{mC}$ antagonizes the negative effect of a Helitron TE in the upstream region to maintain ROS1 expression. Furthermore, $\mathrm{mC}$ at the ROS1 TSS is also targeted by ROS1 itself. Consequently, ROS1 TSS methylation acts as a sensor of the RdDM-ROS1 balance to fine-tune ROS1 expression and in turn the genome-wide methylation pattern (Lei et al., 2015; Williams et al., 2015). In the situation where the effect of ROS1 dominates, a reduction of ROS1 level will be triggered to mitigate the anti-silencing effect and vice versa.

Another example of feedback regulation is the relationship between transcription and H3K9 demethylation by IBM1. As mentioned above, the loss of $\mathrm{mCH} /$ H3K9me2 within TEs in the suvh4 or cmt3 mutants is partially suppressed by $i b m 1$ mutation, and these TEs that are antagonistically regulated by SUVH4/CMT3 and IBM1 are transcriptionally activated in suvh4 or cmt3 (Inagaki et al., 2010). These results suggest that transcription triggers the IBM1 function to demethylate H3K9me2 even in TEs. This will make a positive feedback loop between H3K9 demethylation and transcription to induce and stabilize active chromatin states and to counteract the establishment of TE silencing (Inagaki et al., 2010; To et al., 2020). Furthermore, accumulation of H3K9me2 in the $i b m 1$ mutant was shown to induce a loss of H3K4me1, which is associated with the bodies of actively transcribed genes, and this loss of H3K4me1 depends on the putative H3K4 demethylase LYSINESPECIFIC DEMETHYLASE1-LIKE 2 (LDL2), a homolog of human Lysine Specific Demethylase1 (LSD1) (Shi et al., 2004; Inagaki et al., 2017). The abnormal phenotypes in the $i b m 1$ mutant were largely suppressed by the loss of $L D L 2$. Therefore, H3K9me2 in the gene bodies induces the removal of H3K4me1 by LDL2, which leads to transcriptional repression and developmental abnormalities (Fig. 1). This pathway seems to play a role in TEs because the loss of $\mathrm{H} 3 \mathrm{~K} 9 \mathrm{me} 2$ induces drastic increases of H3K4me1 in the transcribed regions of TEs (Inagaki et al., 2017). Crosstalk between silencing (H3K9me2) and anti-silencing (H3K4me1) marks is regulated by demethylases for each mark (IBM1 and LDL2, respectively).

\section{IMPLICATION IN ENVIRONMENTAL RESPONSES}

The dynamic nature of silencing and anti-silencing as discussed above prompts one to speculate that it may be involved in adaptation to the environment. Wholegenome DNA methylation analyses in hundreds of natural accessions of Arabidopsis have shown that variation of DNA methylation is rich in immunity genes (Kawakatsu et al., 2016). This is also true for presence/absence variation of TEs in natural accessions (Quadrana et al., 2016). These results highlight the impacts of epigenome regulation, which often targets TEs, on immunity against pathogens in natural environments. It was reported that infection by the bacterial pathogens Pseudomonas syringae pv. tomato DC3000 (Pst DC3000) and Pst DC3000 $(a v r P p h B)$ or treatment with the defense hormone salicylic acid causes widespread changes of DNA methylation, most of which are found at the 5' and 3' borders of genes, and in intergenic TEs (Dowen et al., 2012). A part of these changes in DNA methylation is associated with pathogen-induced expression alterations of neighboring genes (Dowen et al., 2012; Yu et al., 2013). ROS1 and RdDM antagonistically regulate these changes in DNA methylation and gene expression (Yu et al., 2013; Halter et al., 2021), and basal immunity against Pst DC3000; the ros 1 mutant is hypersensitive to Pst DC3000, and this hypersensitivity is suppressed by RdDM-defective $d c l 2$ dcl3 double mutation (Halter et al., 2021). These results show that modulation of DNA methylation by ROS1 and RdDM mediates pathogen-induced expression of immunity genes and resistance against pathogens. Mutants for regulators of DNA methylation (DDM1, CMT3 and RdDM genes) tend to show resistance to the obligate biotrophic oomycete Hyaloperonospora arabidopsidis (Hpa), whereas the ros1 mutant shows hypersensitivity (López Sánchez et al., 2016). Accordingly, these mutants show altered $\mathrm{Hpa}$-induced gene expression. Collectively, these observations indicate that infection-induced reprogram- 
ming of DNA methylation is an important part of the defense response, although its precise mechanisms and biological importance are still largely unknown.

The developmental abnormalities in the $i b m 1$ mutant (but not in the suvh or cmt mutants) highlight the importance of H3K9 demethylation in normal development (Saze et al., 2008). The genes upregulated in the $i b m 1$ mutant and suppressed by the $l d l 2$ mutation are significantly enriched for genes involved in defense responses to pathogens such as bacterias and fungi (Inagaki et al., 2017). Therefore, the anti-silencing mechanism involving IBM1 may be involved in adaptation to biotic stress conditions, such as stress memory and priming (Espinas et al., 2016). Another JmjC family H3K9 demethylase gene, JMJ27, in Arabidopsis is transcriptionally upregulated upon infection by the virulent bacterial pathogen Pst DC3000 and is required for resistance to bacterial pathogens (Dutta et al., 2017). JMJ27 likely mediates pathogen-responsive gene expression through the removal of H3K9me from the key regulator(s) of defense responses.

Another locus rich in TE insertion polymorphism in nature is FLOWERING LOCUS C (FLC) (Quadrana et al., 2016). The expression of FLC, a flowering repressor, is controlled by a plethora of epigenome marks and epigenetically silenced after prolonged cold in winter (Whittaker and Dean, 2017; Wu et al., 2020). The silencing of FLC is not reversed even after the plant experiences warmth in spring, reflecting the epigenetic nature of the FLC silencing (Sheldon et al., 2000; Bastow et al., 2004). FLC is reactivated in developing seeds for the next generation (Sheldon et al., 2008; Crevillén et al., 2014). Many silencing and anti-silencing factors participate in transcriptional control of $F L C$ to determine its correct transcription level both in warmth and in cold (Zhao et al., 2005; Ko et al., 2010; Jiang et al., 2011; Yun et al., 2012; Gan et al., 2014; Yang et al., 2014; Wu et al., 2020).

One important factor in the regulation of $F L C$ silencing is long noncoding RNA species that are transcribed at the FLC locus (Swiezewski et al., 2009; Heo and Sung, 2011; Kim and Sung, 2017). These include a set of antisense RNAs called COOLAIR, which is transcriptionally activated in response to cold and is involved in the silencing of sense FLC transcription (Swiezewski et al., 2009; Csorba et al., 2014; Zhao et al., 2021). One chromatin regulator connecting COOLAIR and FLC silencing is FLOWERING LOCUS D (FLD), another Arabidopsis homolog of human LSD1 (He et al., 2003; Liu et al., 2007a). FLD removes H3K4me1 from the transcribed region of the FLC/COOLAIR locus, which is presumably triggered by COOLAIR transcription (Liu et al., 2007a; Inagaki et al., 2021). Interestingly, antisense transcription-triggered demethylation of H3K4me1 by FLD is not specific to the FLC locus but is also seen in many other loci that produce antisense transcripts, most of which are readthrough transcripts from convergently transcribed downstream genes (Inagaki et al., 2021). Therefore, FLD perhaps coordinates overlapping transcription between convergently arranged genes by removing the gene bodyassociated histone mark H3K4me1, and this mechanism could be utilized by plants to control flowering through regulation of the FLC/COOLAIR locus. Such a novel silencing pathway may serve as an adaptive genome response to environmental fluctuation by regulating other loci that produce antisense RNAs.

\section{PERSPECTIVE}

I have summarized the factors involved in shaping epigenomes mainly in Arabidopsis, and discussed the functions and regulations of these factors. Growing evidence suggests the dynamic nature of epigenome regulations and their regulatory mechanisms have been elucidated as discussed in this review. There are many other regulators/modifications that I was not able to mention in this review but have interesting functions and regulatory mechanisms. Harnessing quantitative (epi)genomic analysis, (epi)genome editing and single-cell technologies will accelerate our quest for a deeper understanding of epigenome regulation and for utilization of the knowledge to engineer plants that behave better in harsh and fluctuating environments.

S. I. is supported by grants from the Japan Science and Technology Agency PRESTO program (no. JPMJPR17Q1) and MEXT KAKENHI (no. 20H05913).

\section{REFERENCES}

Allis, C. D., and Jenuwein, T. (2016) The molecular hallmarks of epigenetic control. Nat. Rev. Genet. 17, 487-500.

Audergon, P. N. C. B., Catania, S., Kagansky, A., Tong, P., Shukla, M., Pidoux, A. L., and Allshire, R. C. (2015) Restricted epigenetic inheritance of H3K9 methylation. Science 348, 132-135.

Bastow, R., Mylne, J. S., Lister, C., Lippman, Z., Martienssen, R. A., and Dean, C. (2004) Vernalization requires epigenetic silencing of FLC by histone methylation. Nature $\mathbf{4 2 7}$, 164-167.

Bauer, M. J., and Fischer, R. L. (2011) Genome demethylation and imprinting in the endosperm. Curr. Opin. Plant Biol. 14, 162-167.

Baumbusch, L. O., Thorstensen, T., Krauss, V., Fischer, A., Naumann, K., Assalkhou, R., Schulz, I., Reuter, G., and Aalen, R. B. (2001) The Arabidopsis thaliana genome contains at least 29 active genes encoding SET domain proteins that can be assigned to four evolutionarily conserved classes. Nucleic Acids Res. 29, 4319-4333.

Bernatavichute, Y. V., Zhang, X., Cokus, S., Pellegrini, M., and Jacobsen, S. E. (2008) Genome-wide association of histone H3 lysine nine methylation with CHG DNA methylation in Arabidopsis thaliana. PLoS One 3, e3156.

Borg, M., Papareddy, R. K., Dombey, R., Axelsson, E., Nodine, M. D., Twell, D., and Berger, F. (2021) Epigenetic reprogram- 
ming rewires transcription during the alternation of generations in Arabidopsis. Elife 10, e61894.

Bourguet, P., Picard, C. L., Yelagandula, R., Pélissier, T., Lorković, Z. J., Feng, S., Pouch-Pélissier, M.-N., Schmücker, A., Jacobsen, S. E., Berger, F., and Mathieu, O. (2021) The histone variant H2A.W and linker histone H1 co-regulate heterochromatin accessibility and DNA methylation. Nat. Commun. 12, 2683.

Calarco, J. P., Borges, F., Donoghue, M. T. A., Van Ex, F., Jullien, P. E., Lopes, T., Gardner, R., Berger, F., Feijó, J. A., Becker, J. D., and Martienssen, R. A. (2012) Reprogramming of DNA methylation in pollen guides epigenetic inheritance via small RNA. Cell 151, 194-205.

Cloos, P. A. C., Christensen, J., Agger, K., Maiolica, A., Rappsilber, J., Antal, T., Hansen, K. H., and Helin, K. (2006) The putative oncogene GASC1 demethylates tri- and dimethylated lysine 9 on histone H3. Nature 442, 307-311.

Cokus, S. J., Feng, S., Zhang, X., Chen, Z., Merriman, B., Haudenschild, C. D., Pradhan, S., Nelson, S. F., Pellegrini, M., and Jacobsen, S. E. (2008) Shotgun bisulphite sequencing of the Arabidopsis genome reveals DNA methylation patterning. Nature 452, 215-219.

Cosby, R. L., Chang, N.-C., and Feschotte, C. (2019) Hosttransposon interactions: conflict, cooperation, and cooption. Genes Dev. 33, 1098-1116.

Crevillén, P., Yang, H., Cui, X., Greeff, C., Trick, M., Qiu, Q., Cao, X., and Dean, C. (2014) Epigenetic reprogramming that prevents transgenerational inheritance of the vernalized state. Nature 515, 587-590.

Csorba, T., Questa, J. I., Sun, Q., and Dean, C. (2014) Antisense COOLAIR mediates the coordinated switching of chromatin states at FLC during vernalization. Proc. Natl. Acad. Sci. USA 111, 16160-16165.

Cuerda-Gil, D., and Slotkin, R. K. (2016) Non-canonical RNAdirected DNA methylation. Nat. Plants 2, 16163.

Deleris, A., Stroud, H., Bernatavichute, Y., Johnson, E., Klein, G., Schubert, D., and Jacobsen, S. E. (2012) Loss of the DNA methyltransferase MET1 Induces H3K9 hypermethylation at PcG target genes and redistribution of H3K27 trimethylation to transposons in Arabidopsis thaliana. PLoS Genet. 8, e1003062.

Dowen, R. H., Pelizzola, M., Schmitz, R. J., Lister, R., Dowen, J. M., Nery, J. R., Dixon, J. E., and Ecker, J. R. (2012) Widespread dynamic DNA methylation in response to biotic stress. Proc. Natl. Acad. Sci. USA 109, E2183-E2191.

Du, J., Johnson, L. M., Groth, M., Feng, S., Hale, C. J., Li, S., Vashisht, A. A., Wohlschlegel, J. A., Patel, D. J., and Jacobsen, S. E. (2014) Mechanism of DNA methylationdirected histone methylation by KRYPTONITE. Mol. Cell 55, 495-504.

Du, J., Johnson, L. M., Jacobsen, S. E., and Patel, D. J. (2015) DNA methylation pathways and their crosstalk with histone methylation. Nat. Rev. Mol. Cell Biol. 16, 519-532.

Du, J., Zhong, X., Bernatavichute, Y. V., Stroud, H., Feng, S., Caro, E., Vashisht, A. A., Terragni, J., Chin, H. G., Tu, A., et al. (2012) Dual binding of chromomethylase domains to H3K9me2-containing nucleosomes directs DNA methylation in plants. Cell 151, 167-180.

Dutta, A., Choudhary, P., Caruana, J., and Raina, R. (2017) JMJ27, an Arabidopsis H3K9 histone demethylase, modulates defense against Pseudomonas syringae and flowering time. Plant J. 91, 1015-1028.

Ebbs, M. L., and Bender, J. (2006) Locus-specific control of DNA methylation by the Arabidopsis SUVH5 histone methyltransferase. Plant Cell 18, 1166-1176.
Erdmann, R. M., and Picard, C. L. (2020) RNA-directed DNA Methylation. PLoS Genet. 16, e1009034.

Espinas, N. A., Saze, H., and Saijo, Y. (2016) Epigenetic control of defense signaling and priming in plants. Front. Plant Sci. 7, 1201.

Feng, S., Cokus, S. J., Zhang, X., Chen, P.-Y., Bostick, M., Goll, M. G., Hetzel, J., Jain, J., Strauss, S. H., Halpern, M. E., et al. (2010) Conservation and divergence of methylation patterning in plants and animals. Proc. Natl. Acad. Sci. USA 107, 8689-8694.

Fodor, B. D., Kubicek, S., Yonezawa, M., O'Sullivan, R. J., Sengupta, R., Perez-Burgos, L., Opravil, S., Mechtler, K., Schotta, G., and Jenuwein, T. (2006) Jmjd2b antagonizes H3K9 trimethylation at pericentric heterochromatin in mammalian cells. Genes Dev. 20, 1557-1562.

Frapporti, A., Pina, C. M., Arnaiz, O., Holoch, D., Kawaguchi, T., Humbert, A., Eleftheriou, E., Lombard, B., Loew, D., Sperling, L., et al. (2019) The Polycomb protein Ezl1 mediates H3K9 and H3K27 methylation to repress transposable elements in Paramecium. Nat. Commun. 10, 2710.

Fu, Y., Kawabe, A., Etcheverry, M., Ito, T., Toyoda, A., Fujiyama, A., Colot, V., Tarutani, Y., and Kakutani, T. (2013) Mobilization of a plant transposon by expression of the transposonencoded anti-silencing factor. EMBO J. 32, 2407-2417.

Gan, E.-S., Xu, Y., Wong, J.-Y., Goh, J. G., Sun, B., Wee, W.-Y., Huang, J., and Ito, T. (2014) Jumonji demethylases moderate precocious flowering at elevated temperature via regulation of FLC in Arabidopsis. Nat. Commun. 5, 5098.

Gendrel, A.-V., Lippman, Z., Yordan, C., Colot, V., and Martienssen, R. A. (2002) Dependence of heterochromatic histone H3 methylation patterns on the Arabidopsis gene DDM1. Science 297, 1871-1873.

Halter, T., Wang, J., Amesefe, D., Lastrucci, E., Charvin, M., Singla Rastogi, M., and Navarro, L. (2021) The Arabidopsis active demethylase ROS1 cis-regulates defence genes by erasing DNA methylation at promoter-regulatory regions. Elife 10, e62994.

He, Y., Michaels, S. D., and Amasino, R. M. (2003) Regulation of flowering time by histone acetylation in Arabidopsis. Science 302, 1751-1754.

Heard, E., and Martienssen, R. A. (2014) Transgenerational epigenetic inheritance: myths and mechanisms. Cell 157, 95-109.

Heo, J. B., and Sung, S. (2011) Vernalization-mediated epigenetic silencing by a long intronic noncoding RNA. Science 331, 76-79.

Holliday, R. (1987) The inheritance of epigenetic defects. Science 238, 163-170.

Hosaka, A., and Kakutani, T. (2018) Transposable elements, genome evolution and transgenerational epigenetic variation. Curr. Opin. Genet. Dev. 49, 43-48.

Hosaka, A., Saito, R., Takashima, K., Sasaki, T., Fu, Y., Kawabe, A., Ito, T., Toyoda, A., Fujiyama, A., Tarutani, Y., et al. (2017) Evolution of sequence-specific anti-silencing systems in Arabidopsis. Nat. Commun. 8, 2161.

Ibarra, C. A., Feng, X., Schoft, V. K., Hsieh, T.-F., Uzawa, R., Rodrigues, J. A., Zemach, A., Chumak, N., Machlicova, A., Nishimura, T., et al. (2012) Active DNA demethylation in plant companion cells reinforces transposon methylation in gametes. Science 337, 1360-1364.

Inagaki, S., and Kakutani, T. (2012) What triggers differential DNA methylation of genes and TEs: contribution of body methylation? Cold Spring Harb. Symp. Quant. Biol. 77, 155-160.

Inagaki, S., Miura-Kamio, A., Nakamura, Y., Lu, F., Cui, X., Cao, 
X., Kimura, H., Saze, H., and Kakutani, T. (2010) Autocatalytic differentiation of epigenetic modifications within the Arabidopsis genome. EMBO J. 29, 3496-3506.

Inagaki, S., Takahashi, M., Hosaka, A., Ito, T., Toyoda, A., Fujiyama, A., Tarutani, Y., and Kakutani, T. (2017) Genebody chromatin modification dynamics mediate epigenome differentiation in Arabidopsis. EMBO J. 36, 970-980.

Inagaki, S., Takahashi, M., Takashima, K., Oya, S., and Kakutani, T. (2021) Chromatin-based mechanisms to coordinate convergent overlapping transcription. Nat. Plants 7, 295-302.

Ito, T., Tarutani, Y., To, T. K., Kassam, M., Duvernois-Berthet, E., Cortijo, S., Takashima, K., Saze, H., Toyoda, A., Fujiyama, A., et al. (2015) Genome-wide negative feedback drives transgenerational DNA methylation dynamics in Arabidopsis. PLoS Genet. 11, e1005154.

Jacob, Y., Bergamin, E., Donoghue, M. T. A., Mongeon, V., LeBlanc, C., Voigt, P., Underwood, C. J., Brunzelle, J. S., Michaels, S. D., Reinberg, D., et al. (2014) Selective methylation of histone $\mathrm{H} 3$ variant $\mathrm{H} 3.1$ regulates heterochromatin replication. Science 343, 1249-1253.

Jacob, Y., Feng, S., LeBlanc, C. A., Bernatavichute, Y. V., Stroud, H., Cokus, S., Johnson, L. M., Pellegrini, M., Jacobsen, S. E., and Michaels, S. D. (2009) ATXR5 and ATXR6 are H3K27 monomethyltransferases required for chromatin structure and gene silencing. Nat. Struct. Mol. Biol. 16, 763-768.

Jacob, Y., Stroud, H., Leblanc, C., Feng, S., Zhuo, L., Caro, E., Hassel, C., Gutierrez, C., Michaels, S. D., and Jacobsen, S. E. (2010) Regulation of heterochromatic DNA replication by histone H3 lysine 27 methyltransferases. Nature $\mathbf{4 6 6}$, 987-991.

Jeddeloh, J. A., Stokes, T. L., and Richards, E. J. (1999) Maintenance of genomic methylation requires a SWI2/SNF2-like protein. Nat. Genet. 22, 94-97.

Jiang, D., and Berger, F. (2017) DNA replication-coupled histone modification maintains Polycomb gene silencing in plants. Science 357, 1146-1149.

Jiang, D., Kong, N. C., Gu, X., Li, Z., and He, Y. (2011) Arabidopsis COMPASS-like complexes mediate histone H3 lysine- 4 trimethylation to control floral transition and plant development. PLoS Genet. 7, e1001330.

Johnson, L. M., Bostick, M., Zhang, X., Kraft, E., Henderson, I., Callis, J., and Jacobsen, S. E. (2007) The SRA methylcytosine-binding domain links DNA and histone methylation. Curr. Biol. 17, 379-384.

Kakutani, T., Jeddeloh, J. A., Flowers, S. K., Munakata, K., and Richards, E. J. (1996) Developmental abnormalities and epimutations associated with DNA hypomethylation mutations. Proc. Natl. Acad. Sci. USA 93, 12406-12411.

Kankel, M. W., Ramsey, D. E., Stokes, T. L., Flowers, S. K., Haag, J. R., Jeddeloh, J. A., Riddle, N. C., Verbsky, M. L., and Richards, E. J. (2003) Arabidopsis MET1 cytosine methyltransferase mutants. Genetics 163, 1109-1122.

Kawakatsu, T., Huang, S.-S. C., Jupe, F., Sasaki, E., Schmitz, R. J., Urich, M. A., Castanon, R., Nery, J. R., Barragan, C., He, Y., et al. (2016) Epigenomic diversity in a global collection of Arabidopsis thaliana accessions. Cell 166, 492-505.

Kawashima, T., and Berger, F. (2014) Epigenetic reprogramming in plant sexual reproduction. Nat. Rev. Genet. 15, 613-624.

Khouider, S., Borges, F., LeBlanc, C., Ungru, A., Schnittger, A., Martienssen, R., Colot, V., and Bouyer, D. (2021) Male fertility in Arabidopsis requires active DNA demethylation of genes that control pollen tube function. Nat. Commun. 12, 410 .

Kim, D.-H., and Sung, S. (2017) Vernalization-triggered intragenic chromatin loop formation by long noncoding RNAs. Dev. Cell 40, 302-312.e4.

Kim, M. Y., and Zilberman, D. (2014) DNA methylation as a system of plant genomic immunity. Trends Plant Sci. 19, $320-326$.

Klose, R. J., Kallin, E. M., and Zhang, Y. (2006) JmjC-domaincontaining proteins and histone demethylation. Nat. Rev. Genet. 7, 715-727.

Ko, J.-H., Mitina, I., Tamada, Y., Hyun, Y., Choi, Y., Amasino, R. M., Noh, B., and Noh, Y.-S. (2010) Growth habit determination by the balance of histone methylation activities in Arabidopsis. EMBO J. 29, 3208-3215.

Köhler, C., and Villar, C. B. R. (2008) Programming of gene expression by Polycomb group proteins. Trends Cell Biol. 18, 236-243.

Kuroki, S., Matoba, S., Akiyoshi, M., Matsumura, Y., Miyachi, H., Mise, N., Abe, K., Ogura, A., Wilhelm, D., Koopman, P., et al. (2013) Epigenetic regulation of mouse sex determination by the histone demethylase Jmjd1a. Science 341, 1106-1109.

Law, J. A., and Jacobsen, S. E. (2010) Establishing, maintaining and modifying DNA methylation patterns in plants and animals. Nat. Rev. Genet. 11, 204-220.

Lei, M., Zhang, H., Julian, R., Tang, K., Xie, S., and Zhu, J.-K. (2015) Regulatory link between DNA methylation and active demethylation in Arabidopsis. Proc. Natl. Acad. Sci. USA 112, 3553-3557.

Lippman, Z., Gendrel, A.-V., Black, M., Vaughn, M. W., Dedhia, N., McCombie, W. R., Lavine, K., Mittal, V., May, B., Kasschau, K. D., et al. (2004) Role of transposable elements in heterochromatin and epigenetic control. Nature 430, 471-476.

Lisch, D. (2009) Epigenetic regulation of transposable elements in plants. Annu. Rev. Plant Biol. 60, 43-66.

Lisch, D., and Bennetzen, J. L. (2011) Transposable element origins of epigenetic gene regulation. Curr. Opin. Plant Biol. 14, 156-161.

Lister, R., O’Malley, R. C., Tonti-Filippini, J., Gregory, B. D., Berry, C. C., Harvey Millar, A., and Ecker, J. R. (2008) Highly integrated single-base resolution maps of the epigenome in Arabidopsis. Cell 133, 523-536.

Liu, F., Quesada, V., Crevillén, P., Bäurle, I., Swiezewski, S., and Dean, C. (2007a) The Arabidopsis RNA-binding protein FCA requires a lysine-specific demethylase 1 homolog to downregulate FLC. Mol. Cell 28, 398-407.

Liu, R., and Lang, Z. (2020) The mechanism and function of active DNA demethylation in plants. J. Integr. Plant Biol. 62, 148-159.

Liu, Y., Taverna, S. D., Muratore, T. L., Shabanowitz, J., Hunt, D. F., and Allis, C. D. (2007b) RNAi-dependent H3K27 methylation is required for heterochromatin formation and DNA elimination in Tetrahymena. Genes Dev. 21, 1530-1545.

López Sánchez, A., Stassen, J. H. M., Furci, L., Smith, L. M., and Ton, J. (2016) The role of DNA (de)methylation in immune responsiveness of Arabidopsis. Plant J. 88, 361-374.

Maison, C., and Almouzni, G. (2004) HP1 and the dynamics of heterochromatin maintenance. Nat. Rev. Mol. Cell Biol. 5, 296-304.

Martínez, G., Panda, K., Köhler, C., and Slotkin, R. K. (2016) Silencing in sperm cells is directed by RNA movement from the surrounding nurse cell. Nat. Plants 2, 16030.

Matzke, M. A., and Mosher, R. A. (2014) RNA-directed DNA methylation: an epigenetic pathway of increasing complexity. Nat. Rev. Genet. 15, 394-408.

Mirouze, M., Reinders, J., Bucher, E., Nishimura, T., Schneeberger, K., Ossowski, S., Cao, J., Weigel, D., Paszkowski, J., and Mathieu, O. (2009) Selective epigenetic control of ret- 
rotransposition in Arabidopsis. Nature 461, 427-430.

Miura, A., Nakamura, M., Inagaki, S., Kobayashi, A., Saze, H., and Kakutani, T. (2009) An Arabidopsis jmjC domain protein protects transcribed genes from DNA methylation at CHG sites. EMBO J. 28, 1078-1086.

Miura, A., Yonebayashi, S., Watanabe, K., Toyama, T., Shimada, H., and Kakutani, T. (2001) Mobilization of transposons by a mutation abolishing full DNA methylation in Arabidopsis. Nature 411, 212-214.

Montgomery, S. A., Tanizawa, Y., Galik, B., Wang, N., Ito, T., Mochizuki, T., Akimcheva, S., Bowman, J. L., Cognat, V., Maréchal-Drouard, L., et al. (2020) Chromatin organization in early land plants reveals an ancestral association between H3K27me3, transposons, and constitutive heterochromatin. Curr. Biol. 30, 573-588.e7.

Mozgova, I., and Hennig, L. (2015) The polycomb group protein regulatory network. Annu. Rev. Plant Biol. 66, 269-296.

Mozzetta, C., Pontis, J., Fritsch, L., Robin, P., Portoso, M., Proux, C., Margueron, R., and Ait-Si-Ali, S. (2014) The histone H3 lysine 9 methyltransferases G9a and GLP regulate polycomb repressive complex 2-mediated gene silencing. Mol. Cell 53, 277-289.

Ni, K., Ren, J., Xu, X., He, Y., Finney, R., Braun, S. M. G., Hathaway, N. A., Crabtree, G. R., and Muegge, K. (2020) LSH mediates gene repression through macroH2A deposition. Nat. Commun. 11, 5647.

Nie, W.-F., Lei, M., Zhang, M., Tang, K., Huang, H., Zhang, C., Miki, D., Liu, P., Yang, Y., Wang, X., et al. (2019) Histone acetylation recruits the SWR1 complex to regulate active DNA demethylation in Arabidopsis. Proc. Natl. Acad. Sci. USA 116, 16641-16650.

Okada, Y., Scott, G., Ray, M. K., Mishina, Y., and Zhang, Y. (2007) Histone demethylase JHDM2A is critical for Tnp1 and Prm 1 transcription and spermatogenesis. Nature 450, 119-123.

Osakabe, A., Jamge, B., Axelsson, E., Montgomery, S. A., Akimcheva, S., Kuehn, A. L., Pisupati, R., Lorković, Z. J., Yelagandula, R., Kakutani, T., et al. (2021) The chromatin remodeler DDM1 prevents transposon mobility through deposition of histone variant H2A.W. Nat. Cell Biol. 23, 391-400.

Park, K., Yvonne Kim, M., Vickers, M., Park, J.-S., Hyun, Y., Okamoto, T., Zilberman, D., Fischer, R. L., Feng, X., Choi, Y., and Scholten, S. (2016) DNA demethylation is initiated in the central cells of Arabidopsis and rice. Proc. Natl. Acad. Sci. USA 113, 15138-15143.

Penterman, J., Zilberman, D., Huh, J. H., Ballinger, T., Henikoff, S., and Fischer, R. L. (2007) DNA demethylation in the Arabidopsis genome. Proc. Natl. Acad. Sci. USA 104, 6752-6757.

Qian, W., Miki, D., Zhang, H., Liu, Y., Zhang, X., Tang, K., Kan, Y., La, H., Li, X., Li, S., et al. (2012) A histone acetyltransferase regulates active DNA demethylation in Arabidopsis. Science 336, 1445-1448.

Quadrana, L., Bortolini Silveira, A., Mayhew, G. F., LeBlanc, C., Martienssen, R. A., Jeddeloh, J. A., and Colot, V. (2016) The Arabidopsis thaliana mobilome and its impact at the species level. Elife 5, e15716.

Ragunathan, K., Jih, G., and Moazed, D. (2015) Epigenetics. Epigenetic inheritance uncoupled from sequence-specific recruitment. Science 348, 1258699.

Richards, E. J. (2006) Inherited epigenetic variation-revisiting soft inheritance. Nat. Rev. Genet. 7, 395-401.

Sasaki, T., Kobayashi, A., Saze, H., and Kakutani, T. (2012) RNAi-independent de novo DNA methylation revealed in Arabidopsis mutants of chromatin remodeling gene DDM1. Plant J. 70, 750-758.

Saze, H., and Kakutani, T. (2007) Heritable epigenetic mutation of a transposon-flanked Arabidopsis gene due to lack of the chromatin-remodeling factor DDM1. EMBO J. 26, 3641-3652.

Saze, H., and Kakutani, T. (2011) Differentiation of epigenetic modifications between transposons and genes. Curr. Opin. Plant Biol. 14, 81-87.

Saze, H., Mittelsten Scheid, O., and Paszkowski, J. (2003) Maintenance of $\mathrm{CpG}$ methylation is essential for epigenetic inheritance during plant gametogenesis. Nat. Genet. 34, 65-69.

Saze, H., Shiraishi, A., Miura, A., and Kakutani, T. (2008) Control of genic DNA methylation by a jmjC domain-containing protein in Arabidopsis thaliana. Science 319, 462-465.

Schoft, V. K., Chumak, N., Choi, Y., Hannon, M., Garcia-Aguilar, M., Machlicova, A., Slusarz, L., Mosiolek, M., Park, J.-S., Park, G. T., et al. (2011) Function of the DEMETER DNA glycosylase in the Arabidopsis thaliana male gametophyte. Proc. Natl. Acad. Sci. USA 108, 8042-8047.

Sheldon, C. C., Hills, M. J., Lister, C., Dean, C., Dennis, E. S., and Peacock, W. J. (2008) Resetting of FLOWERING LOCUS $C$ expression after epigenetic repression by vernalization. Proc. Natl. Acad. Sci. USA 105, 2214-2219.

Sheldon, C. C., Rouse, D. T., Finnegan, E. J., Peacock, W. J., and Dennis, E. S. (2000) The molecular basis of vernalization: the central role of FLOWERING LOCUS C (FLC). Proc. Natl. Acad. Sci. USA 97, 3753-3758.

Shi, Y., Lan, F., Matson, C., Mulligan, P., Whetstine, J. R., Cole, P. A., Casero, R. A., and Shi, Y. (2004) Histone demethylation mediated by the nuclear amine oxidase homolog LSD1. Cell 119, 941-953.

Singer, T., Yordan, C., and Martienssen, R. A. (2001) Robertson's Mutator transposons in A. thaliana are regulated by the chromatin-remodeling gene Decrease in DNA Methylation (DDM1). Genes Dev. 15, 591-602.

Slotkin, R. K., and Martienssen, R. (2007) Transposable elements and the epigenetic regulation of the genome. Nat. Rev. Genet. 8, 272-285.

Slotkin, R. K., Vaughn, M., Borges, F., Tanurdzić, M., Becker, J. D., Feijó, J. A., and Martienssen, R. A. (2009) Epigenetic reprogramming and small RNA silencing of transposable elements in pollen. Cell 136, 461-472.

Sorida, M., Hirauchi, T., Ishizaki, H., Kaito, W., Shimada, A., Mori, C., Chikashige, Y., Hiraoka, Y., Suzuki, Y., Ohkawa, Y., et al. (2019) Regulation of ectopic heterochromatinmediated epigenetic diversification by the JmjC family protein Epe1. PLoS Genet. 15, e1008129.

Stroud, H., Do, T., Du, J., Zhong, X., Feng, S., Johnson, L., Patel, D. J., and Jacobsen, S. E. (2014) Non-CG methylation patterns shape the epigenetic landscape in Arabidopsis. Nat. Struct. Mol. Biol. 21, 64-72.

Sun, Q., and Zhou, D.-X. (2008) Rice jmjC domain-containing gene JMJ706 encodes H3K9 demethylase required for floral organ development. Proc. Natl. Acad. Sci. USA 105, 13679-13684.

Swiezewski, S., Liu, F., Magusin, A., and Dean, C. (2009) Coldinduced silencing by long antisense transcripts of an Arabidopsis Polycomb target. Nature 462, 799-802.

Tang, K., Lang, Z., Zhang, H., and Zhu, J.-K. (2016) The DNA demethylase ROS1 targets genomic regions with distinct chromatin modifications. Nat. Plants 2, 16169.

Tateishi, K., Okada, Y., Kallin, E. M., and Zhang, Y. (2009) Role of Jhdm2a in regulating metabolic gene expression and obe- 
sity resistance. Nature 458, 757-761.

To, T. K., Nishizawa, Y., Inagaki, S., Tarutani, Y., Tominaga, S., Toyoda, A., Fujiyama, A., Berger, F., and Kakutani, T. (2020) RNA interference-independent reprogramming of DNA methylation in Arabidopsis. Nat. Plants 6, 1455-1467.

Torres-Garcia, S., Yaseen, I., Shukla, M., Audergon, P. N. C. B., White, S. A., Pidoux, A. L., and Allshire, R. C. (2020) Epigenetic gene silencing by heterochromatin primes fungal resistance. Nature 585, 453-458.

Trewick, S. C., Minc, E., Antonelli, R., Urano, T., and Allshire, R. C. (2007) The JmjC domain protein Epe1 prevents unregulated assembly and disassembly of heterochromatin. EMBO J. 26, 4670-4682.

Tsukada, Y.-I., Fang, J., Erdjument-Bromage, H., Warren, M. E., Borchers, C. H., Tempst, P., and Zhang, Y. (2006) Histone demethylation by a family of JmjC domain-containing proteins. Nature 439, 811-816.

Tsukahara, S., Kobayashi, A., Kawabe, A., Mathieu, O., Miura, A., and Kakutani, T. (2009) Bursts of retrotransposition reproduced in Arabidopsis. Nature 461, 423-426.

Turck, F., Roudier, F., Farrona, S., Martin-Magniette, M.-L., Guillaume, E., Buisine, N., Gagnot, S., Martienssen, R. A., Coupland, G., and Colot, V. (2007) Arabidopsis TFL2/LHP1 specifically associates with genes marked by trimethylation of histone H3 lysine 27. PLoS Genet. 3, e86.

Veluchamy, A., Rastogi, A., Lin, X., Lombard, B., Murik, O., Thomas, Y., Dingli, F., Rivarola, M., Ott, S., Liu, X., et al. (2015) An integrative analysis of post-translational histone modifications in the marine diatom Phaeodactylum tricornutum. Genome Biol. 16, 102.

Vongs, A., Kakutani, T., Martienssen, R. A., and Richards, E. J. (1993) Arabidopsis thaliana DNA methylation mutants. Science 260, 1926-1928.

Wang, J., Reddy, B. D., and Jia, S. (2015) Rapid epigenetic adaptation to uncontrolled heterochromatin spreading. Elife 4, e06179.

Whittaker, C., and Dean, C. (2017) The FLC locus: a platform for discoveries in epigenetics and adaptation. Annu. Rev. Cell Dev. Biol. 33, 555-575.

Wiles, E. T., and Selker, E. U. (2017) H3K27 methylation: a promiscuous repressive chromatin mark. Curr. Opin. Genet. Dev. 43, 31-37.

Williams, B. P., Pignatta, D., Henikoff, S., and Gehring, M. (2015) Methylation-sensitive expression of a DNA demethylase gene serves as an epigenetic rheostat. PLoS Genet. 11, e1005142.

Wu, Z., Fang, X., Zhu, D., and Dean, C. (2020) Autonomous pathway: FLOWERING LOCUS C repression through an antisense-mediated chromatin-silencing mechanism. Plant Physiol. 182, 27-37.

Xiao, J., and Wagner, D. (2015) Polycomb repression in the regulation of growth and development in Arabidopsis. Curr. Opin. Plant Biol. 23, 15-24.

Yamane, K., Toumazou, C., Tsukada, Y.-I., Erdjument-Bromage, H., Tempst, P., Wong, J., and Zhang, Y. (2006) JHDM2A, a JmjC-containing H3K9 demethylase, facilitates transcription activation by androgen receptor. Cell 125, 483-495.

Yang, H., Howard, M., and Dean, C. (2014) Antagonistic roles for H3K36me3 and H3K27me3 in the cold-induced epigenetic switch at Arabidopsis FLC. Curr. Biol. 24, 1793-1797.

Yelagandula, R., Stroud, H., Holec, S., Zhou, K., Feng, S., Zhong,
X., Muthurajan, U. M., Nie, X., Kawashima, T., Groth, M., et al. (2014) The histone variant H2A.W defines heterochromatin and promotes chromatin condensation in Arabidopsis. Cell 158, 98-109.

Yu, A., Lepère, G., Jay, F., Wang, J., Bapaume, L., Wang, Y., Abraham, A.-L., Penterman, J., Fischer, R. L., Voinnet, O., et al. (2013) Dynamics and biological relevance of DNA demethylation in Arabidopsis antibacterial defense. Proc. Natl. Acad. Sci. USA 110, 2389-2394.

Yun, J.-Y., Tamada, Y., Kang, Y. E., and Amasino, R. M. (2012) Arabidopsis trithorax-related3/SET domain GROUP2 is required for the winter-annual habit of Arabidopsis thaliana. Plant Cell Physiol. 53, 834-846.

Zemach, A., Kim, M. Y., Hsieh, P.-H., Coleman-Derr, D., EshedWilliams, L., Thao, K., Harmer, S. L., and Zilberman, D. (2013) The Arabidopsis nucleosome remodeler DDM1 allows DNA methyltransferases to access H1-containing heterochromatin. Cell 153, 193-205.

Zemach, A., McDaniel, I. E., Silva, P., and Zilberman, D. (2010) Genome-wide evolutionary analysis of eukaryotic DNA methylation. Science 328, 916-919.

Zemach, A., and Zilberman, D. (2010) Evolution of eukaryotic DNA methylation and the pursuit of safer sex. Curr. Biol. 20, R780-R785.

Zhang, C., Du, X., Tang, K., Yang, Z., Pan, L., Zhu, P., Luo, J., Jiang, Y., Zhang, H., Wan, H., et al. (2018a) Arabidopsis AGDP1 links H3K9me2 to DNA methylation in heterochromatin. Nat. Commun. 9, 4547.

Zhang, H., Lang, Z., and Zhu, J.-K. (2018b) Dynamics and function of DNA methylation in plants. Nat. Rev. Mol. Cell Biol. 19, 489-506.

Zhang, X., Germann, S., Blus, B. J., Khorasanizadeh, S., Gaudin, V., and Jacobsen, S. E. (2007) The Arabidopsis LHP1 protein colocalizes with histone H3 Lys27 trimethylation. Nat. Struct. Mol. Biol. 14, 869-871.

Zhao, S., Cheng, L., Gao, Y., Zhang, B., Zheng, X., Wang, L., Li, P., Sun, Q., and Li, H. (2019a) Plant HP1 protein ADCP1 links multivalent H3K9 methylation readout to heterochromatin formation. Cell Res. 29, 54-66.

Zhao, X., Xiong, J., Mao, F., Sheng, Y., Chen, X., Feng, L., Dui, W., Yang, W., Kapusta, A., Feschotte, C., et al. (2019b) RNAidependent Polycomb repression controls transposable elements in Tetrahymena. Genes Dev. 33, 348-364.

Zhao, Y., Zhu, P., Hepworth, J., Bloomer, R., AntoniouKourounioti, R. L., Doughty, J., Heckmann, A., Xu, C., Yang, H., and Dean, C. (2021) Natural temperature fluctuations promote COOLAIR regulation of FLC. Genes Dev. 35, 888-898.

Zhao, Z., Yu, Y., Meyer, D., Wu, C., and Shen, W.-H. (2005) Prevention of early flowering by expression of FLOWERING LOCUS C requires methylation of histone H3 K36. Nat. Cell Biol. 7, 1256-1260.

Zhu, J.-K. (2009) Active DNA demethylation mediated by DNA glycosylases. Annu. Rev. Genet. 43, 143-166.

Zilberman, D., Coleman-Derr, D., Ballinger, T., and Henikoff, S. (2008) Histone H2A.Z and DNA methylation are mutually antagonistic chromatin marks. Nature 456, 125-129.

Zofall, M., and Grewal, S. I. S. (2006) Swi6/HP1 recruits a JmjC domain protein to facilitate transcription of heterochromatic repeats. Mol. Cell 22, 681-692. 